\title{
Computed-Tomography-Based Analysis of Voids in SnBi57Ag1 Solder Joints and Their Influence on the Reliability
}

\author{
Miriam Rauer • Antje Volkert • Timo Schreck • \\ Stefan Härter • Michael Kaloudis
}

Submitted: 9 August 2013/Published online: 15 March 2014

(C) ASM International 2014

\begin{abstract}
The first area of research in this article focuses on the characterization of solder joints that contain voids by means of computed tomography (CT). This non-destructive test method made it possible to detect both cracks and voids in solder joints, to define their precise positions, and to capture the void volume of each void. In addition to $\mathrm{CT}$, we carried out metallographic examinations so that we could demonstrate the interaction of both methods. In the process, CT was used to localize the defect and metallography to display the defect in high resolution. The article goes on to discuss the question of whether voids have an effect on the thermo-mechanical reliability of SnBi57Ag1 solder joints. For this purpose, the solder joints were first classified by their void area ratio using radioscopy. In order to analyze the effect of the void area ratio on the reliability of the joint, the assembly underwent an accelerated aging process through thermal shock testing according to IPC 9701. Subsequently, the shocked assemblies were sheared. With the shear values after 1000 cycles, we were able to show that the voids affect the reliability of the SnBi57Ag1 solder joints only slightly and that the joints were hardly damaged. By means of CT examinations performed prior to the thermal shocks, cracks starting from the meniscus tip could be attributed to the temperature changes. These cracks may be crucial when they occur with cracks found on macrovoids inside the meniscus.
\end{abstract}

M. Rauer $(\bowtie) \cdot$ A. Volkert · T. Schreck · M. Kaloudis Packaging and Interconnection Laboratory, University of Applied Sciences Aschaffenburg, Aschaffenburg, Germany e-mail: miriam.rauer@h-ab.de

\section{S. Härter}

Institute for Factory Automation and Production Systems (FAPS), University of Erlangen-Nuremberg, Nuremberg, Germany
Keywords Computed tomography · Solder joints . Voids · Reliability

\section{Introduction}

Owing to legal regulations, tin-silver-copper (SAC) alloys with a melting point of $217{ }^{\circ} \mathrm{C}$ have established as a quasistandard in the lead-free surface mounted technology (SMT) in recent years. Especially when processing temperaturesensitive materials and components, the corresponding high soldering temperatures are often not really acceptable, and thus solder alloys with a low melting point are required. Alloys based on tin and bismuth are suitable; they have a melting point of $139^{\circ} \mathrm{C}$ in the eutectic composition, and, therefore, provide a low-melting-point alternative to SAC solders, as long as the operating temperature allows it. The mechanical properties of these alloys, such as tensile modulus and tensile strength, are comparable with those of $\mathrm{SnPb} 40$ alloy [1]. By adding elements as silver the SnBi alloy's ductility can be improved [2]. As a result, alloys of the composition SnBi57Ag1 have a high potential for application in SMT [3].

In connection with the introduction of lead-free technology, an increase of voids in the solder joints has been observed, which leads to a reduction of the actual connector cross sections in the solder joint, reducing the mechanical stability and the reliability [4]. In addition, heat dissipation can be impaired in large solder joints due to a high void ratio [5]. Studies with chip resistors of SnBi58 solder joints have shown that voids have no significant relevance for the shearing resistance [6]. This research project will examine the effect of voids in SnBi57Ag1 solder joints on 1206 surface mounted device (SMD) resistors and their influence on the thermomechanical reliability by subjecting test vehicles to accelerated aging in the form of a temperature change test. 
Fig. 1 Basic construction of the soldered resistors

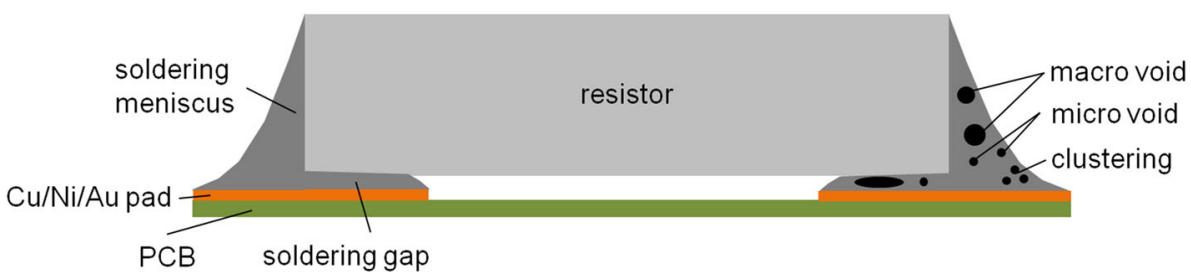

Various methods of analysis such as metallography and radiographic methods such as radioscopy as well as computed tomography (CT) serve to characterize the solder joints before and after aging. CT, which makes it possible to analyze and illustrate the inner and outer structures of the object to be examined in three dimensions (3D), has increasingly become an effective instrument in inspection technology in recent years. However, in many cases of application it makes sense to combine the non-destructive CT and destructive inspection technologies $[7,8]$. The resolution of the usual laboratory computer tomograph is not sufficient for some issues within the scope of reliability examinations so that, additionally, metallographic inspection methods with high-definition light and scanning electron microscopy (SEM) as well as elementary analyses have been applied [9].

In this research project, the efficiency of $\mathrm{CT}$ will be shown by detecting voids and cracks in SnBi57Ag1 solder joints. The CT data will enable us to quantitatively define the precise position and the void volume in the SnBi57Ag1 solder joints. The quality and reliability of the solder joints will be assessed using shearing force examinations and metallographic analyses and correlated with the CT data.

\section{Experimental Methods}

\section{Preparation of the Solder Joints}

The SMDs considered here are chip resistors of the 1206 $(3.2 \mathrm{~mm} \times 1.6 \mathrm{~mm})$ type from the manufacturer RS. The inner bottom electrodes were $\mathrm{Ag}$ with a barrier layer of $\mathrm{Ni}$ coated with tin. Once the SnBi57Ag1 solder paste F360 Bi57Ag1-90M 30 had been printed using a stencil technique on an FR4 circuit board with copper/nickel/gold metallization, the SMD components were mounted and the reflow soldering was performed in a convection oven in air. For the production of solder joints with various void ratios, the composition of the soldering paste was varied by adding sodium hydrogen carbonate $\left(\mathrm{NaHCO}_{3}\right)$.

Figure 1 shows the basic construction of the soldered assembly. During the soldering process, the solder climbs up next to the component and forms the so-called soldering meniscus. The area between the component bottom and the printed circuit board (PCB) pad is referred to as the soldering gap. The number of voids and their position and size in the soldering meniscus as well as in the soldering gap is of particular interest. The void size can be differentiated into micro- and macro-voids, microvoids being small voids with a diameter of up to $100 \mu \mathrm{m}$ and macrovoids being large voids with a diameter of over $100 \mu \mathrm{m}$ up to $200 \mu \mathrm{m}$.

\section{Metallography}

To analyze the solder joint quality, metallographic microsections were made, and the structure was examined under an optical microscope as well as a scanning electron microscope. The samples were sanded using 220-, 1000-, and 2500-grit $\mathrm{SiC}$ sandpaper and polished using diamond suspension with a graining of $3 \mu \mathrm{m}$ as well as $\mathrm{SiO}_{2}$ suspension. In order to illustrate the intermetallic phases better, the microsection sample was etched in nital. On the basis of the SEM with higher resolution, the individual structures were characterized by means of energy-dispersive X-ray microanalysis (EDX). With the help of the resulting EDX spectra, it was possible to analyze the phase compositions and compare them with literature data.

\section{Radioscopy}

Radioscopy was used for determining the void ratio in the solder joints produced. The strength of radioscopy lies in the fact that it can be performed easily and fastly. However, the two-dimensional (2D) radioscopic pictures are limited when trying to detect volume errors since they do not provide any information on the depth of the error. Consequently, CT was used as well.

\section{Computed Tomography}

Figure 2 shows the principle of an industrial X-ray computer tomograph. The $\mathrm{x}$-radiation in the form of a cone beam emitted by the X-ray tube penetrates the components and is partially absorbed by the individual materials of the object, resulting in attenuation of the radiation on the detector. As the component rotates $360^{\circ}$ during a measurement, the detector takes a multitude of $2 \mathrm{D}$ projection images, from which a 3D data set of voxels is reconstructed by means of suitable algorithms and powerful computers [10].

Once the data set has been reconstructed, the volume of the test object and the inner structures can be illustrated 
Fig. 2 Functional principle of an X-ray computer tomograph

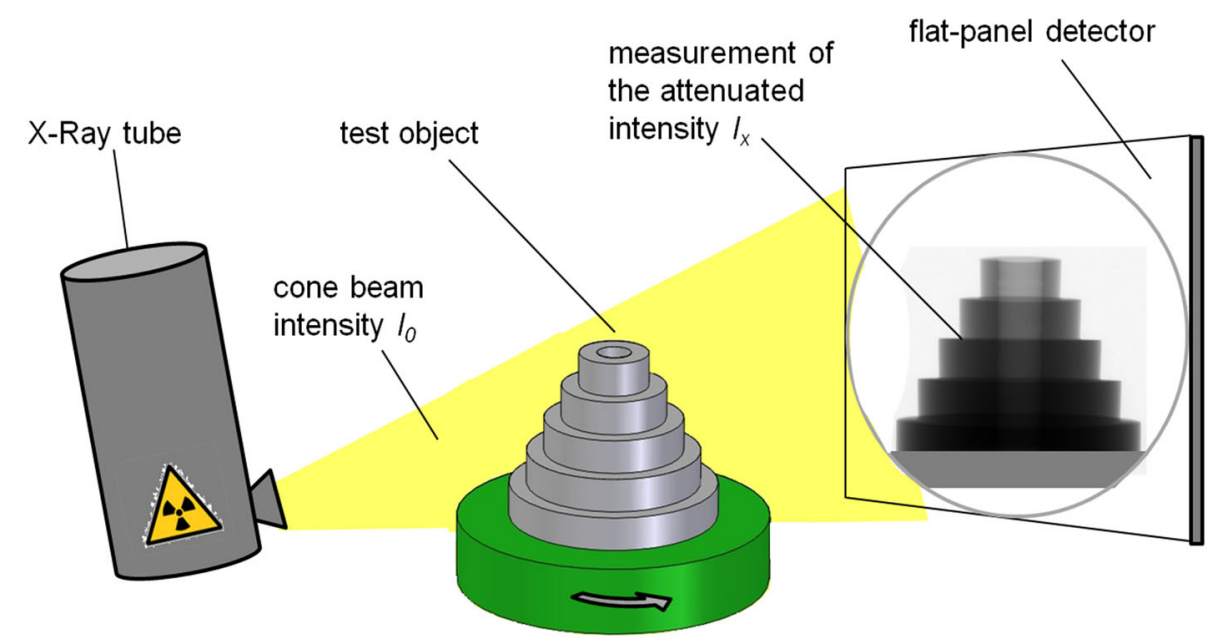

and each layer can be analyzed for defects with the help of the software application VG Studio MAX 2.1 by Volume Graphics GmbH, Heidelberg, Germany. Additional analysis options such as porosity and inclusion analysis provide the opportunity to detect both voids and inclusions by the use of various algorithms. They are then highlighted by means of a size-dependent false-color image in 2D and $3 \mathrm{D}$ views of the data set and consolidated in a void size statistic. For each individual defect, the volume, position, dimensions, and surface can be determined [11].

The $130 \mathrm{kV}$ computer tomograph exaCT ${ }^{\circledR S}$ by Wenzel Volumetrik, Singen, Germany, can deal with voxel resolutions of down to $5 \mu \mathrm{m}$ and thus belongs to the category of microcomputer tomographs. As a result, the illustration of details in the sub-micrometer range is limited. In order to still examine structures in high resolution, it is advisable to firstly narrow down the interesting area using CT and then produce a specific metallographic microsection of it. As metallography is a destructive method and grinding past entails an irreversible information loss, the extra effort and expense of CT are often justified. There is also the danger that when observing the wrong microsection the sample may be classified as error-free since the error pattern is situated in a microsection that is still hidden or has already been ground off [8]. Unlike radioscopy, CT makes it possible to detect the 3D position of an imperfection, which may be crucial for the type of failure.

\section{Accelerated Aging and Shear Test}

In order to determine the influence of voids on the thermomechanical reliability of solder joints, the assemblies were subjected to a standardized thermal shock test with a temperature ranging from -40 to $+125^{\circ} \mathrm{C}$ and a cycle period of one hour in accordance with IPC 9701. Owing to the changes in the ambient temperature and the different heat expansion coefficients of the materials of the assembly used, mechanical tension and fatigue of the solder joints occur. Individual components were analyzed after the aging test using CT and metallography. Additionally, shear experiments were conducted to assess the effect of the temperature changes on the solder joint's strength between the component connections and the soldering pads of the substrate. For this purpose, the soldered component is removed from the circuit board by a mechanical shearing load using a shearing chisel, and the shearing force needed to do so is recorded. The shearing takes place initially and after 250, 500, 750, and 1000 cycles.

\section{Results and Discussion}

Characterization of the 3D Void Distribution in SnBi57Ag1 Solder Joints

On the basis of a tomographed 1206 SMD resistor (denomination R1), the possibilities of a 3D characterization of voids will be outlined in the following. For this purpose, the resistor R1 was analyzed at the highest resolution of $5 \mu \mathrm{m}$ of the computer tomograph exaCT®S. The top parts of Fig. 3 show the 3D view of the soldered SMD resistor in which the cross sections illustrated below are sketched. Physically, it is a challenge to illustrate lowabsorbency and high-absorbency materials in CT at the same time. For evaluation of the quality of the solder joints, the measuring parameters have been chosen in such a way that the highly absorbing solder joints and the resistor layer are seen. However, the low-absorbency ceramic base of aluminum oxide and the FR4 circuit board cannot be illustrated by means of those measuring parameters. The horizontal cross section in Fig. 3a shows both micro- and macro-voids in the soldering gap. As can be seen in the 3D view, the soldering meniscus climbs up evenly next to the component. When observing the cross section in Fig. 3a, 


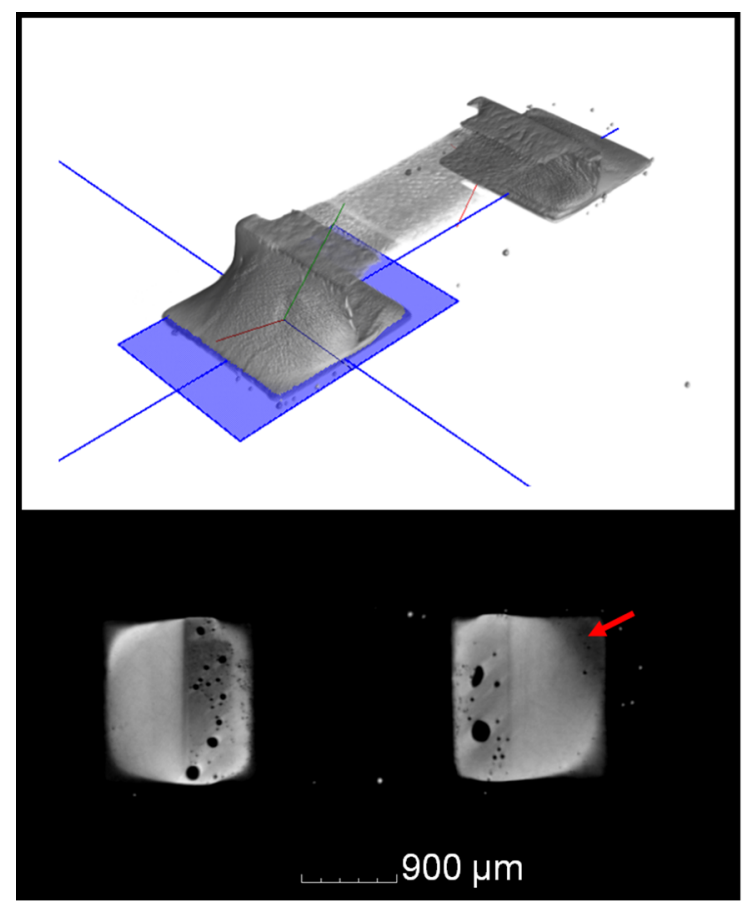

(a)

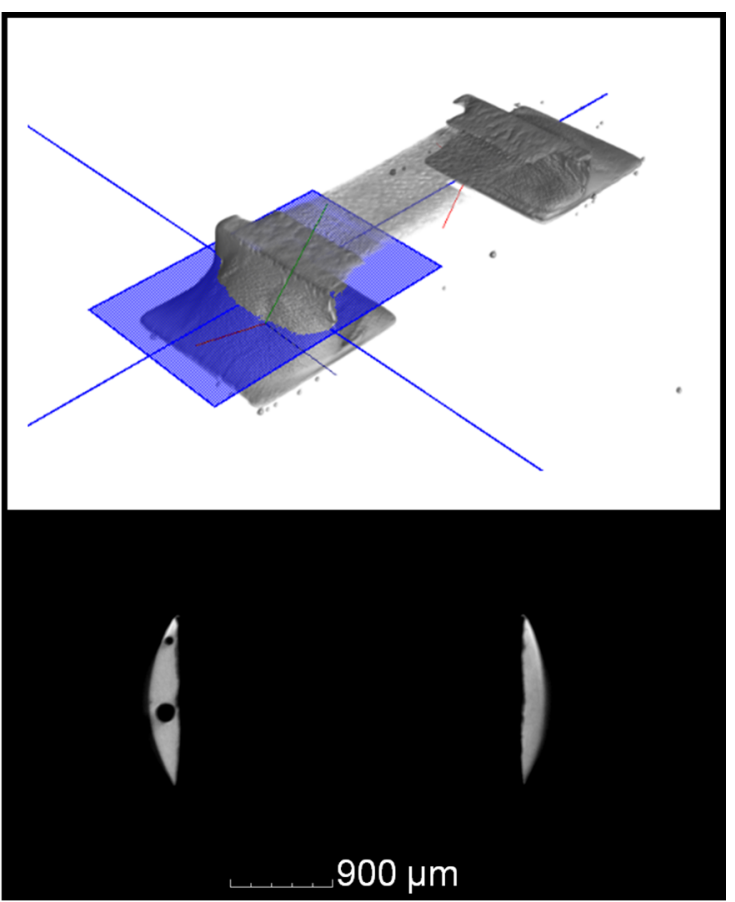

(b)

Fig. 3 3D view of the 1206 SMD resistor R1 with cross section indicated (above) and the corresponding CT cross section (below). The cross section in (a) shows voids in the soldering gap while the cross section in (b) further above shows voids in the soldering meniscus

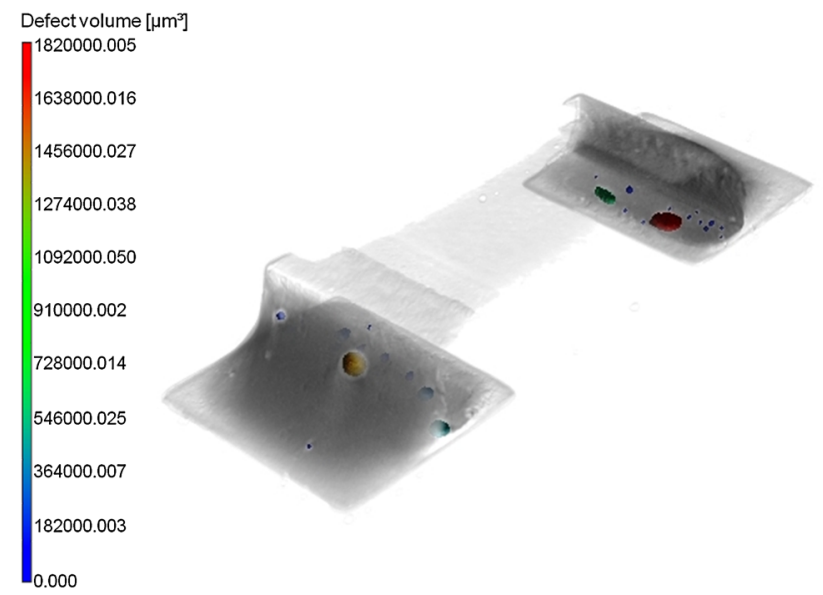

Fig. 4 3D view of the 1206 SMD resistor R1 with illustration of voids in relation to size

no voids can be seen in the central area of the soldering pad. Above the central area, the material-intensive soldering meniscus runs upward. Along the outer edge of the soldering pad in the region of the tapering meniscus, on the other hand, microvoids with a diameter of up to $70 \mu \mathrm{m}$ can be seen (see arrow). Figure $3 b$ shows two voids with diameters of 80 and $170 \mu \mathrm{m}$ further up in the soldering meniscus on the left. However, the highest void concentration can be found in the soldering gap. The reason for this is probably that the voids are trapped in the joint at this position due to the component above and cannot escape upward during the soldering process.

Figure 4 shows the $3 \mathrm{D}$ view of the same resistor $\mathrm{R} 1$ after the void analysis was carried out. The voids are colored in relation to their volume. For the dimensions of the defects please refer to the corresponding color-coded value ranges. The $3 \mathrm{D}$ view confirms the result that the majority of the voids are located in the soldering gap and only occasional macrovoids are in the meniscus.

Not only the voids but also the complete volume of the solder joint can be measured, so the ratio between the total void volumes $V_{\text {Void }}$ and the total joint volume $V_{\text {Total Joint }}$ can be calculated:

Void volume ratio $=\frac{\sum_{i=1}^{n} V_{\text {Void } i}}{V_{\text {TotalJoint }}}$.

The void volume ratio was calculated with $0.8 \%$ in the case of the resistor $\mathrm{R} 1$.

In the horizontal cross section in Fig. 5, the voids are now colored in relation to their sizes. Most of them are microvoids. Only two large voids are located in the right soldering pad directly under the component, their volumes being $1,800,000$ and $600,000 \mu^{3}$. The mapped cross sections 1 and 2 indicate the positions of the vertical cross sections underneath through the two large voids. As can be seen, the volumes are not ball-shaped but the voids are limited at the top and the bottom by the component and the 


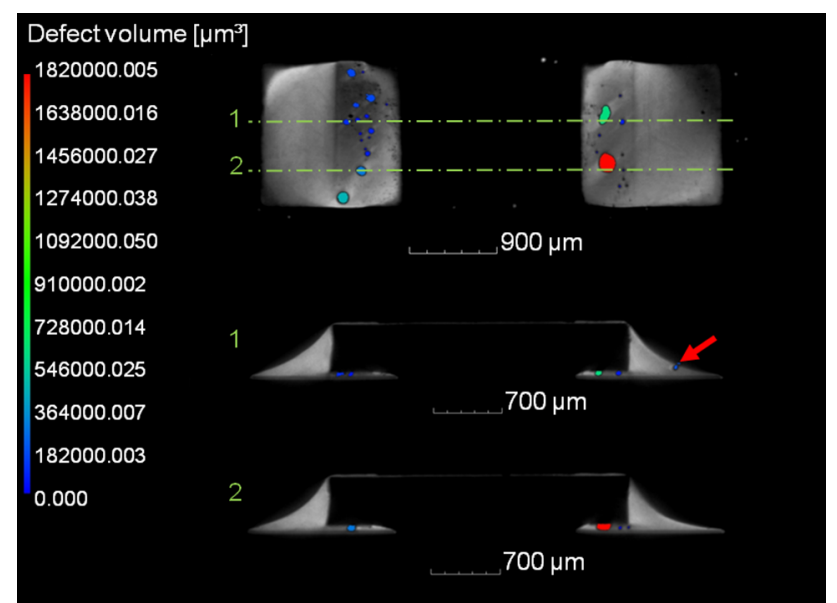

Fig. 5 Horizontal cross section through the soldering gap of the 1206 resistor R1 with illustration of the voids in relation to their sizes and indicated vertical cross sections shown underneath

circuit board, resulting in a cylinder-like geometry. Beside the voids in the soldering gap, the vertical cross section 1 shows a void with a diameter of $70 \mu \mathrm{m}$ in the right meniscus (see arrow). While the voids illustrated in Fig. 3b are at the top of the meniscus near the component, the void near the soldering pad is localized in the tapering meniscus. The CT data and analysis options show that the 3D void distribution can be captured precisely.

\section{CT for Crack Detection}

Not only voids but also cracks with a certain size can be detected in solder joints using CT. By way of example, this will be shown in the following with the aid of a 2512 resistor which was soldered onto an FR4 circuit board with an SAC alloy. Figure 6a shows the CT of the cross section of the considerably damaged resistor after 1000 thermal shock cycles. As can be seen, a crack in the soldering gap is spreading from the void along the component metallization first below and then at the side of the component. The crack leaves the joint via the meniscus. However, it does not travel as far as the point of the meniscus but exits the meniscus transversely at the same level as the middle of the component. Such a CT scan may serve as a basis for a subsequent metallographic target preparation, as illustrated in Fig. 6b. Due to the higher resolution of the method, the structures discussed can now be recognized considerably better. This example clearly shows the effectiveness of a combination of the CT and metallography methods: CT for error localization and metallography for high-resolution illustration. In principle, the result shown can also be achieved using only metallography. However, in that case a number of microsections are often required to capture the solder volume and there is a risk that errors may be
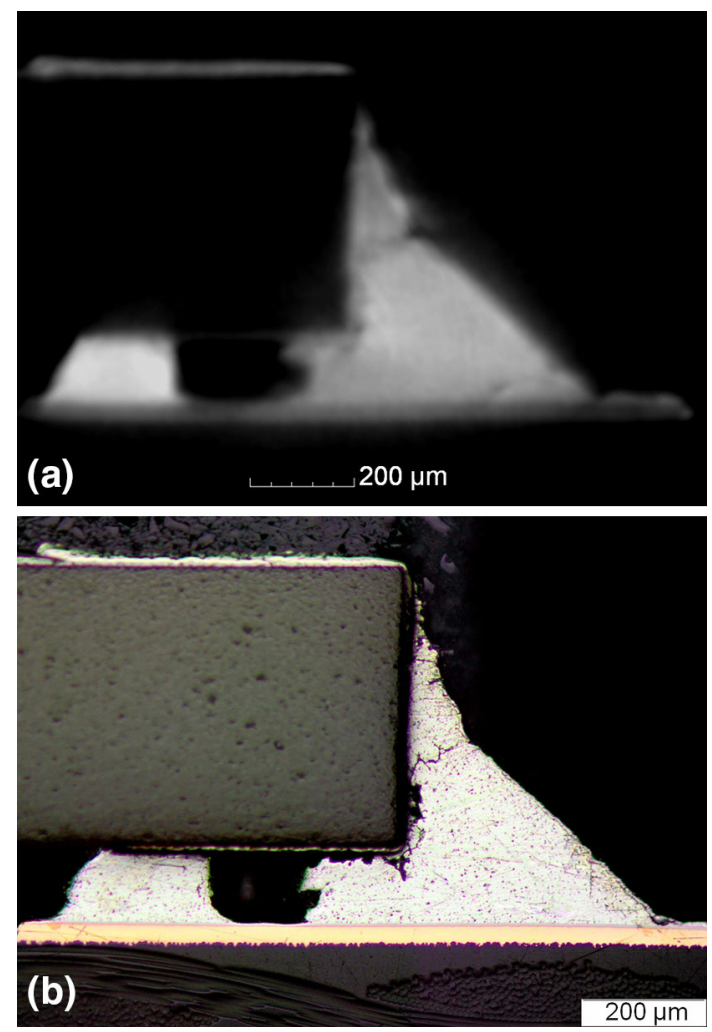

Fig. 62512 resistor soldered with SAC joint on FR4 circuit board after 1000 thermal shocks: (a) CT of the cross section and (b) Metallographic microsection

overlooked. The use of CT reduces this risk and also drastically reduces the preparation cost.

\section{Classification of the Solder Joints by their Void Ratio}

In order to be able to classify them, all solder joints were examined using radioscopy. On the X-ray images, the void areas were measured manually with the aid of the image analysis software Analysis Docu by Olympus. On the basis of these data, the solder joints were then classified by their void ratios. The void ratio is calculated by forming the quotient from the total of all void areas $A_{\text {Void }}$ and the total soldering pad area $A_{\text {Soldering pad area: }}$

Void area ratio $=\frac{\sum_{i=1}^{n} A_{\mathrm{Void} i}}{A_{\text {Soldering Pad Area }}}$.

Based on the void ratios established, the samples were classified into three categories $(<2,2-3 \%$, and $>3-5.5 \%)$. The different category widths result from the fact that sparsely populated categories with a void ratio under $2 \%$ and from over 3 to $5.5 \%$ were consolidated.

Figure 7 shows the radioscopy of the soldered 1206 SMD resistor R1 already observed in Figs. 2, 3, and 4 with measured areas. Unlike in the CT, here the darker grayscale values are assigned to the heavily absorbing 


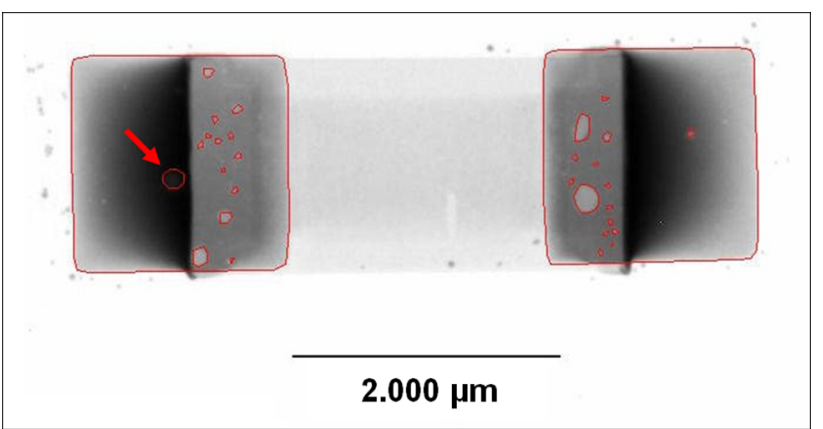

Fig. 7 Radioscopy of the soldered 1206 SMD resistor R1 with manually measured void and soldering pad areas

Table 1 Number of sheared components per cycle and void area ratio

\begin{tabular}{lccccc}
\hline & \multicolumn{5}{c}{ Number of cycles } \\
\cline { 2 - 6 } Void area ratio & 0 & 250 & 500 & 750 & 1000 \\
\hline$<2 \%$ & 14 & 20 & 18 & 25 & 15 \\
$2-3 \%$ & 28 & 27 & 30 & 30 & 28 \\
$>3-5.5 \%$ & 11 & 18 & 23 & 15 & 25 \\
\hline
\end{tabular}

materials. By means of the highlighted void from Fig. 7, a benefit of CT can be demonstrated. With the aid of the radioscopy available, it is not possible to define the exact position of the void. Specifically, the vertical distance between the void and the circuit board pad cannot be clarified. Only when CT is used statements about the third dimension can be done and thus the exact location of the void can be determined, as illustrated in Fig. 3 .

Tomographic examinations provide more information than radioscopy. However, as they are more costly than radioscopy due to the measurement principle, the latter is usually preferred in major spot checks.

\section{Examination of the Thermo-Mechanical Reliability of SnBi57Ag1 Solder Joints}

The components were first stressed with temperature cycles between -40 and $+125{ }^{\circ} \mathrm{C}$ to determine the mechanical strength of the components. After 0, 250, 500, 750, and 1000 cycles, a partial quantity of the components was sheared in each case in order to document the impact of the aging. Table 1 illustrates the number of sheared components per cycle and void area ratio.

Based on the void area ratios classified by means of radioscopies, examination of the effect of the void ratio on the mechanical stability of the solder joints can be done. The bar chart in Fig. 8 shows the averages of the maximum shearing strengths after $0,250,500,750$, and 1000 cycles of each void area class. The Student's $t$ distribution was

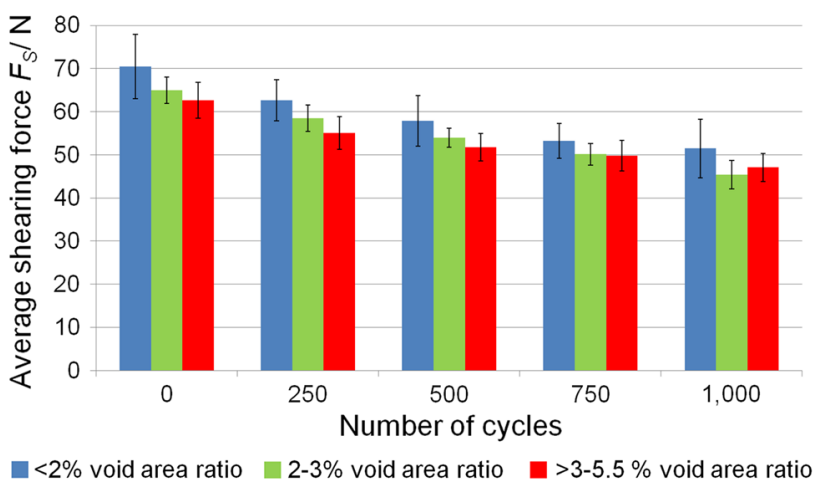

Fig. 8 Average value of the maximum shearing force on 1206 resistors after temperature cycles of -40 to $+125{ }^{\circ} \mathrm{C}$ with classified void area ratio. The error indicators represent the \pm Student's $t$ distributions

Table 2 Classification of the fracture modes

\begin{tabular}{l}
\hline \multicolumn{1}{c}{ Fracture modes } \\
\hline 1: Demolition of the component metallization \\
2: Component-solder interface \\
3: Fracture in the solder \\
1/2: Mixed fracture of demolition of the component metallization and \\
component-solder interface \\
1/3: Mixed fracture of demolition of the component metallization and \\
fracture in the solder
\end{tabular}

chosen as an error indicator in this case. As can be seen, the shearing forces decrease as the aging progresses. Consequently, with 0 to 1000 cycles and a void ratio of under $2 \%$, the mean value of shearing force of $70.5 \mathrm{~N}$ drops by $27 \%$, the force of $65 \mathrm{~N}$ drops by $30 \%$ with a void ratio of $2-3 \%$ and the force of $62.6 \mathrm{~N}$ drops by $25 \%$ with a void ratio of over $3 \%$ to $5.5 \%$. Up to 500 cycles, it can be observed that the shearing forces of all void classifications decrease. As the joints age there are shearing values that do not follow this course anymore. With 750 cycles, the average shearing values of the 2-3 and $>3-5.5 \%$ classes are almost identical. After 1000 cycles the shearing forces of components with a void area ratio of $2-3 \%$ are lower compared to the shearing forces of components with a void area ratio of $>3-5.5 \%$. However, when observing the error indicators it becomes apparent that the decrease in the shearing values is in the range of the error bars.

While the shearing force of the SnBi57Ag1 solder paste decreased by a maximum of $30 \%$ after 1000 cycles compared to the initial shearing value, the shearing values in the case of SAC joints $(\mathrm{SnAg} 3 \mathrm{Cu} 0.5, \mathrm{SnAg} 4 \mathrm{Cu} 0.5)$ can decrease by up to $40 \%$ according to the literature $[12,13]$.

As well as the shear strength, the types of failures of the sheared components and the PCB were investigated. The 
Table 3 Number of components according to fracture mode as well as the number of temperature shock cycles

\begin{tabular}{lrrrrr}
\hline & \multicolumn{5}{c}{ Fracture mode } \\
\cline { 2 - 6 } Number of cycles & 1 & 2 & 3 & $1 / 2$ & $1 / 3$ \\
\hline 0 & $\ldots$ & 0 & 0 & 27 & 26 \\
250 & $\ldots$ & 1 & 2 & 32 & 30 \\
500 & $\ldots$ & 4 & 13 & 26 & 28 \\
750 & $\ldots$ & 5 & 7 & 49 & 9 \\
1000 & $\ldots$ & 12 & 23 & 25 & 8 \\
\hline
\end{tabular}
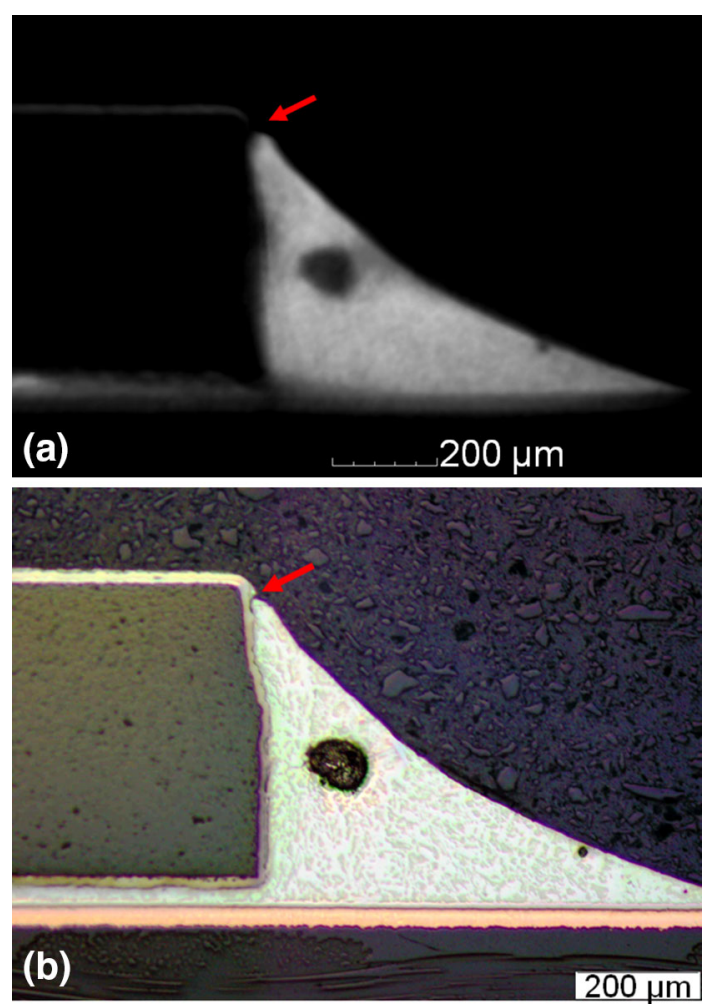

Fig. 9 Resistor R2 after 1000 temperature change cycles: (a) CT cross section and (b) Metallographic microsection

failure types are classified into the fracture modes in Table 2.

Table 3 shows the number of sheared components assigned to the particular fracture modes as well as the number of temperature shock cycles. In the case of low cycles most of the sheared parts failed due to mixed fracture of demolition of the component metallization and component-solder interface or mixed fracture of demolition of the component metallization and fracture in the solder (fracture modes $1 / 2$ and 1/3). At higher cycles more of fracture modes 2 (component-solder interface) and 3 (fracture in the solder) appeared.

By way of example, Fig. 9 shows a CT cross section and a metallographic microsection of the same plane of a shocked resistor R2 after 1000 cycles. The CT image in Fig. 9a was taken at a maximum resolution of $5 \mu \mathrm{m}$ and already suggests a developing crack at the top of the soldering meniscus. A metallographic examination confirmed the findings. As no damage can be seen in the area of the macrovoid of this microsection either, the solder joint is evaluated as unimpaired apart from the crack mentioned.

However, as it could not be ruled out that an impairment in a subjacent microsection existed, the complete component volume was examined with the aid of the CT data. Microsections were made of the areas that suggested impairments. An example can be seen in Fig. 10. In this microsection, one void is located in the soldering meniscus and another in the soldering gap; they will be illustrated again at higher resolution in the detailed view. The irregularities around the edge of the void in the meniscus had occurred before the thermal shock cycles during the soldering process, as the void was open toward the outside. CT makes it possible to analyze the areas before and behind the microsection viewed here. It becomes apparent that the freely protruding solder joint at the edge of the void (see mark) is tied to the remaining solder joint further to the rear. The detailed view at the bottom right shows a microvoid underneath the component in the soldering gap where no cracks occurred.

A crack in the top of the meniscus can also be found in further samples after 1000 cycles (see SEM image of resistor R1 in Fig. 11). The detailed views on the right show the part above the crack in the point of the meniscus in higher resolution and, in addition, the part below a macrovoid with a diameter of $160 \mu \mathrm{m}$ in the soldering meniscus. At the edge of the macrovoid, a crack can be seen starting from it. The situation is similar to that of resistor 2, the difference being, however, that in the case of R2 the macrovoid does not reach the component metallization or the intermetallic layer of the soldering joint (cf. Fig. 9).

The $\mathrm{CT}$ view of resistor $\mathrm{R} 1$ before the temperature cycle test (see Fig. 12) did not show cracks either at the point of the meniscus or at the macrovoid. As a result, one can conclude that the crack formation is due to the thermal shocks. It is to be expected that cracks of that kind will continue to grow as the cycle number is increased and will limit the reliability of the solder joint. Furthermore, the crack starting from the top of the meniscus may continue to grow as well and, together with the macrovoid, may contribute to a considerable weakening of the solder joint. As a consequence, macrovoids that reach from the edge of the soldering meniscus to the component should be avoided by all means. As discussed above, in this context a radioscopic examination does not provide sufficient information. On the other hand, fast CT examinations in high resolution under production conditions are still under development in 


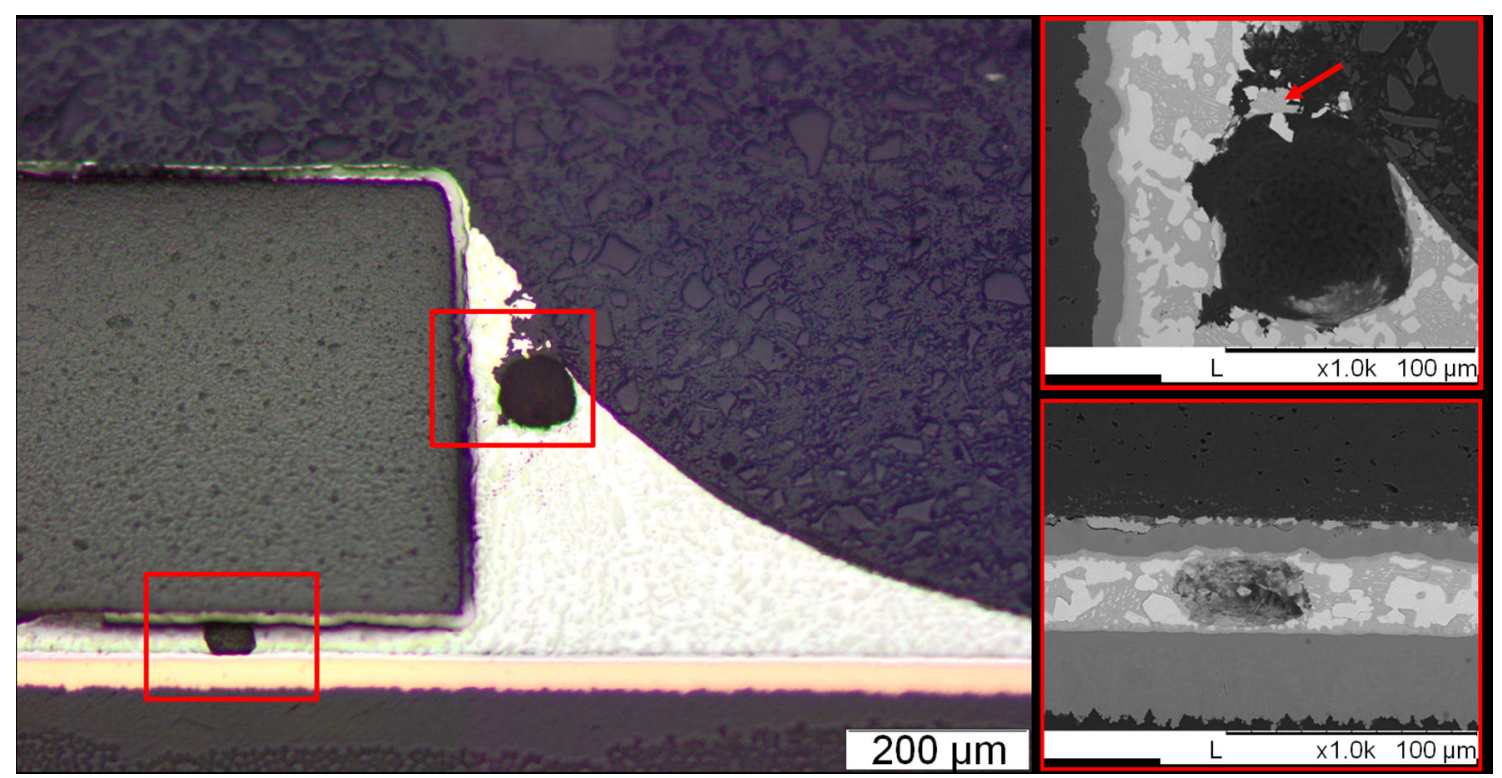

Fig. 10 Another metallographic microsection of the SMD resistor R2 from Fig. 9 after 1000 cycles with a detailed view of the voids in the meniscus and the soldering gap

Fig. 111206 resistor R1 after 1000 thermal shocks. SEM image with detailed views. These show a crack in the point of the meniscus as well as a crack starting from the macrovoid

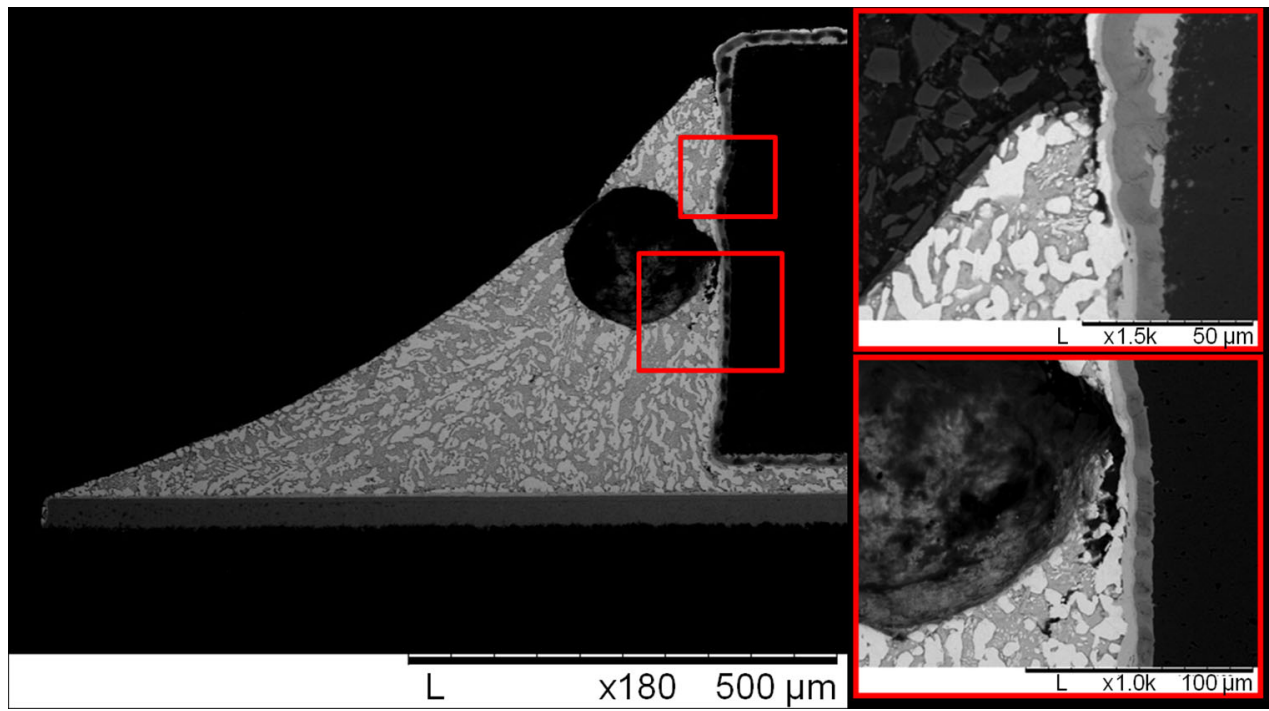

the electronics industry today. One solution could be to measure macrovoids in the meniscus by means of radioscopy and to define them as principally not permissible if they have a certain maximum size. The size still permissible must be defined dependent on both the component size and the alloy used as well as on the reliability requirements.

Taken as a whole, we can record that the SnBi57Ag1 solder joints show only minor impairments after 1000 thermal shocks. Although cracks that must have been formed by the thermal shocks could be found at the top of the meniscus, both the shearing tests and the metallographic examinations show that these are not yet crucial. Macrovoids in the meniscus can be the starting point of cracks whereas smaller voids in the soldering gap, it seems, do not lead to crack growth. Voids in the meniscus that reach from the component to the solder joint area appear to be especially critical, particularly when they interact with the cracks starting from the point of the meniscus.

\section{Structural Conditions After 1000 Cycles}

After it became apparent that the strength values of the SnBi57Ag1 solder joints hardly decreased in the shearing test despite voids, and after only a few non-critical cracks were found even after 1000 cycles, the structural conditions were examined after 1000 cycles. No defects could be 


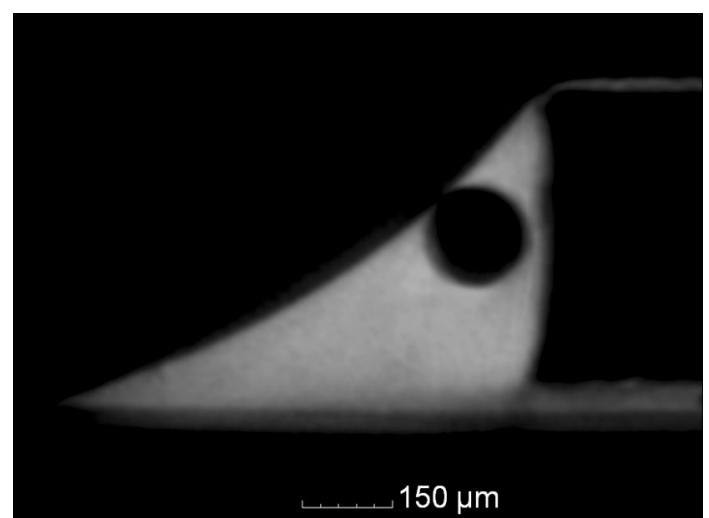

Fig. 121206 resistor R1. The CT cross section of the SMD resistor does not show any cracks before the temperature cycles
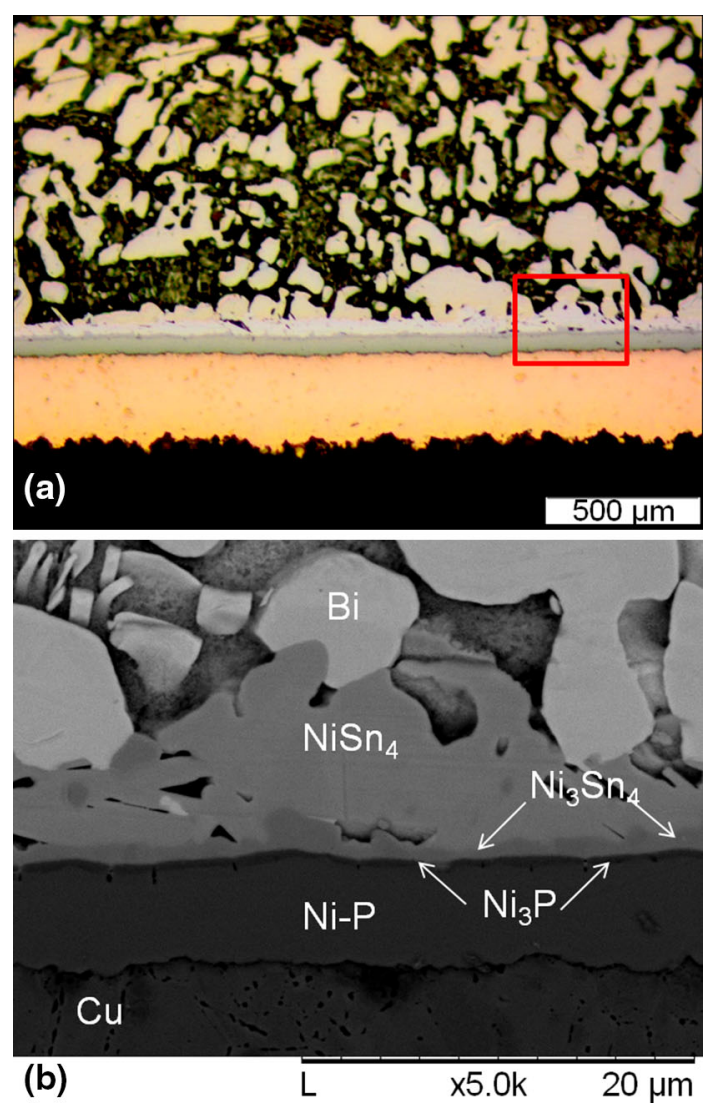

Fig. 13 (a) Light microscopic image of the solder/substrate boundary surface after 1000 cycles; (b) Corresponding SEM image with elements and phases characterized by means of EDX

found in the structure at microscale (see Fig. 13). The allocation of the phases corresponds to the literature [14].

\section{Summary}

On the basis of 1206 SMD resistors, the study has shown that $\mathrm{CT}$ is an effective method of characterizing the void distribution in solder joints in 3D. It makes it possible to precisely localize the void position as well as to determine the void volumes and illustrate them using a size-dependent false-color image. By means of detecting cracks in solder joints, we were able to demonstrate the combination of CT and metallography. CT examinations form the basis of subsequent metallographic target preparations; in the process CT localizes the error and metallography illustrates it in high resolution.

By means of radioscopic images of the SnBi57Ag1 solder joints, we first measured the void areas and then classified the solder joints according to their void area ratios. After that, the soldered components were subjected to a temperature cycling test from -40 to $+125^{\circ} \mathrm{C}$ and sheared after defined cycle numbers. It was demonstrated that both temperature cycles and void area ratio in the solder joints have little influence on the shearing values. Only minor impairments could be determined after 1000 thermal shocks in the SnBi57Ag1 solder joints by means of $\mathrm{CT}$, metallography, and SEM images. Cracks in the top of the meniscus which originated due to the thermal shocks are classified as not crucial, as shown in shearing tests and metallographic examinations. Macrovoids in the soldering meniscus, on the other hand, may be the starting point of cracks. They are considered crucial especially if they reach from the component to the soldering joint surface and if cracks also start from the meniscus point. However, no cracks were detected at smaller voids in the soldering gap.

The above-described proceeding is already possible for smaller component types with appropriate CT systems. Inline CTs are yet available for the detection of pores and inclusions in castings. The ongoing improvements of CT systems such as higher voxel resolutions in the submicrometer range, faster scan times, and the further development of inline CT systems will make CT to an essential test method for the electronic industry in future.

\section{References}

1. M. Abtew, G. Selvaduray, Lead-free solders in microelectronics. Mater. Sci. Eng. 27, 95-141 (2000)

2. K. Suganuma, The current status of lead-free soldering, ESPEC Technology Report, No. 13, pp. 1-8

3. J. Lau, J. Gleason, V. Schroeder, G. Henshall, W. Dauksher, B. Sullivan, Design, materials, and assembly process of high-density packages with a low-temperature lead-free solder ( $\mathrm{SnBiAg}$ ). Solder. Surf. Mount Technol. 20 (2), (Emerald Group Publishing Limited, 2008), pp. 11-20

4. U. Pape, Reduzierung von Poren in Lötverbindungen durch neue Löttechnologien, Elektronische Baugruppen und Leiterplatten EBL 2008-Systemintegration und Zuverlässigkeit, 55, K.-D. Lang, Ed., 4. DVS/GMM-Fachtagung, 13-14 February 2008 (Fellbach, VDE Verlag GMBH, 2008), pp. 151-156

5. T. Lauer, Porenarme Lötverbindungen zur Zuverlässigkeitssteigerung und optimierten Entwärmung von Flachbaugruppen, 
Elektronische Baugruppen und Leiterplatten EBL 2010 - Zuverlässigkeit und Systemintegration, 265, K.-D. Lang, Ed. 5. DVS/GMM-Fachtagung, 24-25 February 2010 (Fellbach, DVS Media GMBH), 2010, pp. 6-9

6. Th. Herzog, K. Wolter, F. Poetzsch, Investigations of void forming and shear strength of Sn42Bi58 solder joints for low cost applications, 53rd Electronic Components and Technology Conference, Proceedings, 27-30 May 2003 (New Orleans, IEEE, 2003), pp. 1738-1745

7. W. Faust, E. Noack, B. Michel, Nano-Computertomographie - ein wertvolles Hilfsmittel bei metallographischen Untersuchungen zur Schadensanalyse mikroelektronischer und mikrotechnischer Komponenten, Fortschritte in der Metallographie, Vol. 40, G. Petzow, Ed., 17-19 September 2008 (Jena), Deutsche Gesellschaft für Materialkunde, Werkstoff-Informationsgesellschaft $\mathrm{mbH}$, 2008, pp. 61-66

8. M. Rauer, T. Schreck, M. Kaloudis, X-ray computed tomography as supporting technology in the failure analysis of press-in connections for electronic assemblies. Pract. Metallogr. 3, 205-221 (2013)

9. R. Löffler, T. Bernthaler, A. Nagel, G. Schneider, 3D-Computertomographie und Materialographie - Potential für angewandte Werkstoffentwicklung und Schadensanalyse, Fortschritte in der
Metallographie, Vol. 39, G. Petzow, Ed., 19-21 September 2007 (Bremen, Deutsche Gesellschaft für Materialkunde, WerkstoffInformationsgesellschaft mbH, 2007), pp. 219-224

10. P. O. Moore, R. Bossi, F. Iddings, G. Wheeler, Nondestructive Testing Handbook: Radiographic Testing, vol. 4, 3rd edn. (American Society for Nondestructive Testing, 2002), p. 303

11. Volume Graphics GmbH, Porositätsanalyse (2013), http://www. volumegraphics.com/de/produkte/vgstudio-max/porositaetsanalyse. html. Accessed on 22 Feb 2013

12. K.-J. Wolter, T. Zerna, St. Wiese, Fehlermechanismen und Prüfverfahren miniaturisierter Lötverbindungen, Ergebnisbericht des BMBF-Verbundprojekts nanoPAL: “Zerstörende und zerstörungsfreie Prüftechnik für die Charakterisierung von nanoskaligen Alterungsmechanismen an hochminiaturisierten Lötverbindungen", System Integration in Electronic Packaging, vol. 9, Detert Verlag, 2009

13. O. Krammer, T. Garami, Reliability investigation of low silver content micro-alloyed SAC solders. 35th International Spring Seminar on Electronics Technology, 9-13 May 2012 (Bad Aussee, Austria), pp. 149-154

14. Ch. Fuchs, T. Schreck, M. Kaloudis, Interfacial reactions between $\mathrm{Sn}-57 \mathrm{Bi}-1 \mathrm{Ag}$ solder and electroless Ni-P/immersion $\mathrm{Au}$ under solid-state aging. J. Mater. Sci. 47(9), 4036-4041 (2012) 